\title{
PERANCANGAN APLIKASI PENYEWAAN LAPANGAN FUTSAL MENGGUNAKAN JAVA NETBEANS
}

\author{
Febriani Safitri $^{1}$, Kursehi Falgenti ${ }^{2}$, Ambar Tri Hapsari ${ }^{3 .}$ \\ ${ }^{1,2,3}$ Fakultas Teknik dan Ilmu Komputer, Universitas Indraprasta PGRI \\ ${ }^{1}$ febrianisafitri28@gmail.com
}

\begin{abstract}
Abstrak
Tujuan Penelitian adalah untuk merancang sistem penyewaan pada Kans Futsal menjadi sistem teraplikasi agar dapat mempercepat proses rekapitulasi dan penyusunan laporan, serta meminimalisir terjadinya keterlambatan pembuatan laporan. Metode penulisan yang digunakan adalah metode grounded research yaitu suatu metode penelitian berdasarkan pada fakta dan menggunakan analisis perbandingan dengan tujuan mengadakan generalisasi empiris menetapkan konsep, membuktikan teori, mengembangkan teori, pengumpulan dan analisis data dalam waktu yang bersamaan. Penulis menarik kesimpulan bawah perancangan aplikasi yang dibangun dapat mempermudah sistem penyewaan di kans futsal menjadi efektif dan efisien.
\end{abstract}

Kata kunci: : Penyewaan, Lapangan Futsal, Java, MySQL

\begin{abstract}
The purpose of this research is to design a leasing system in Kans Futsal to be an applied system in order to accelerate the process of recapitulation and compilation of reports, as well as minimizing the occurrence of delays in preparing reports. The writing method used is a grounded research method which is a research method based on facts and uses comparative analysis with the aim of carrying out empirical generalizations to set concepts, prove theories, develop theories, collect and analyze data at the same time. The author draws the conclusion that the design of an application that is built can facilitate the rental system in the futsal chance to be effective and efficient.
\end{abstract}

Keywords: Rental, Futsal field Java, MySQL

\section{Pendahuluan}

Perkembangan teknologi saat ini semakin berkembang pesat, pemenuhan kebutuhan terhadap suatu informasi saat ini tidak lepas dari pemakaian dan pemanfaatan komputer, dibandingkan dengan proses sebelumnya, dengan adanya sistem informasi yang terkomputerisasi, maka pekerjaan yang dilakukan akan menjadi lebih cepat, tepat dan akurat. Selain itu, perkembangan teknologi informasi dan komunikasi mendorong lahirnya pelayanan-pelayanan atau berbagai jenis kegiatan yang berbasis internet dan elektronik.
Pada Kans Futsal yang dalam pengolahan sistem datanya masih belum efektif atau masih manual dan sejauh ini belum ada sistem informasi aplikasi dekstop, sistem inputannya masih bersifat pencatatan pada buku besar, pembuatan laporan belum akurat. Berdasarkan urairan diatas, penulis tertarik untuk membuat skripsipenelitian dengan judul "Perancangan Aplikasi Penyewaan Lapangan Futsal Menggunakan Java Netbeans".

Dari uraian pada tujuan penelitian, maka peneliti memberi sejumlah tujuan penelitian sebagai berikut:

1. Tujuan dari penelitian ini adalah untuk 
merancang dan membangun aplikasi penyewaan lapangan futsal di Kans Futsal.

2. Penelitian ini membuat sebuah aplikasi untuk membangun sistem penyewaan lapangan yang lebih efektif dan efisien.

3. Dengan membuat sebuah aplikasi ini dapat merancang laporan yang aktif dan akurat di Kans Futsal

Manfaat penelitian ini adalah sebagai berikut :

Untuk mengembangkan sistem pemesanan lapangan futsal agar sistem pemesanan lapangan futsal yang diterapkan tidak manual menggunakan catatan buku dan memanfaatkan pengembangan aplikasi sederhana sehingga pemesanan lapangan futsal dapat berjalan efektif dan efisien.

2.Penelitian ini untuk membantu dan mempermudah dalam pembuatan laporan dan data-data di Kans Futsal.

3.Hasil ini dapat menjadi bahan referensi, bagi pihak-pihak yang akan mengkaji informasi dan melakukan penelitian yang sama.

\section{Metode Penelitian}

Menurut (Darmadi, 2013), "Metode penelitian adalah suatu cara ilmiah untuk mendapatkan data dengan tujuan kegunaan tertentu". Pada penelitian ini, penulis menggunakan metode penelitian Grounded research. Grounded research adalah suatu metode penelitian yang mendasarkan diri kepada fakta yang menggunakan analisis perbandingan untuk mengandakan generalisasi teori, dan mengembangkan teori dimana pengumpulan data dan analisis data berjalan pada waktu yang bersamaan. Dari definisi diatas, maka terlihat bahwa metode yang digunakan dalam Grounded research adalah reaksi terhadap metode penelitian yang asasnya verifikasi teori. Dalam Grounded Research data merupakan sumber teori,dan teori disebut Grounded Research Karena teori tersebut berdasarkan fakta.

Tujuan Grounded Research adalah untuk melakukan generalisasi empiris, menetapkan konsep-konsep, membuktikan teori dan mengembangkan teori. Metode yang digunakan dalam Grounded Research adalah studi-studi perbandingan berjutuan untuk menentukan seberapa jauh suatu gejala berlaku umum. Penelitian juga bertujuan untuk mempelajari suatu kasus atau gejala dengan membandingkan gejala atau kasus tersebut dengan kasus gejala serupa. Perbandingan demikian akan menjelaskan unsure-unsur baru khas dari kasus yang sedang dipelajari.

\section{Metode Pengumpulan Data}

Metode yang digunakan untuk keterangan dan rancangan program yang dibutuhkan untuk perancangan sistem informasi berbasis computer, antara lain :

\section{Metode Lapangan}

Dilakukan peneliti secara langsung untuk mengumpulkan data-data yang berhubungan dengan perancangan aplikasi penyewaan lapangan futsal dengan melakukan observasi yang mempelajari dan mengamati dan mempelajari sistem yang berjalan di kans futsal serta dilengkapi dengan wawancara dengan pemilik ptempat penyewaan lapangan futsal untuk mendapatkan data yang tidak dapat diraih dengan observasi dan untuk melengkapi data yang didapatkan dari observasi.

\section{Metode Kepustakaan}

Dilakukan dengan cara mempelajari buku-buku literature mengenai analisis dan mendesain sebuah sistem, dan mempelajari sistem dari aplikasi sistem informasi lain yang serupa dengan aplikasi yang akan dibuat.

\section{Hasil dan Pembahasan}

Menurut Sutabri (2016:116) "Rancangan Data Flow Diagram (DFD) adalah suatu network yang menggambarkan suatu system automat atau komputerisasi, manualisasi, atau gabungan dari keduanya, yang penggambarannya disusun dalam bentuk kumpulan komponen sistem yang saling berhubungan sesuai aturan mainnya." Berikut adalah rancangan DFD yang peneliti usulkan:

\section{Diagram Konteks}

Menurut Kristanto (2011:55) "Diagram konteks adalah sebuah diagram sederhana yang menggambarkan hubungan antara entity 
luar, masukkan dan keluaran dari sistem". Diagram ini dibuat untuk menggambarkan sistem secara umum dari keseluruhan sistem yang ada. Diagram Konteks yang diusulkan pada Penyewaan Lapangan Futsal di Kans Futsal, yatitu:
1) Pengurus Lapangan Futsal

2) Member

3) Non Member

4) Pemilik Lapangan Futsal

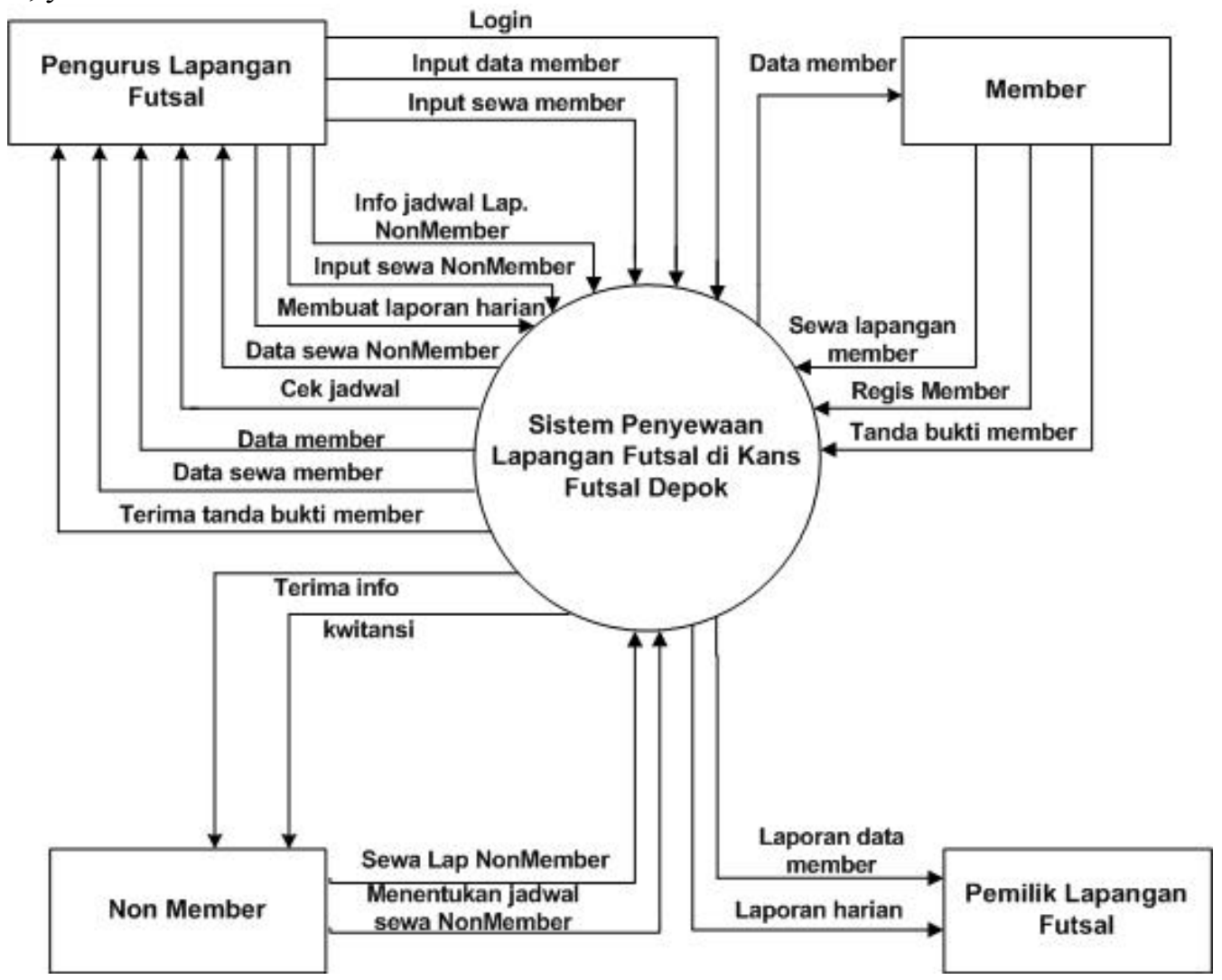

Gambar.1 Diagram Konteks yang Diusulkan

\section{Diagram Nol}

Diagram ini dibuat untuk menggambarkan tahapan proses yang ada di dalam Diagram Konteks, yang penyebarannya lebih terperinci. Tahapan proses tersebut diantranya adalah:
1) User
2) Pendataan
3) Cek Jadwal
4) Penyewaan
5) Laporan 


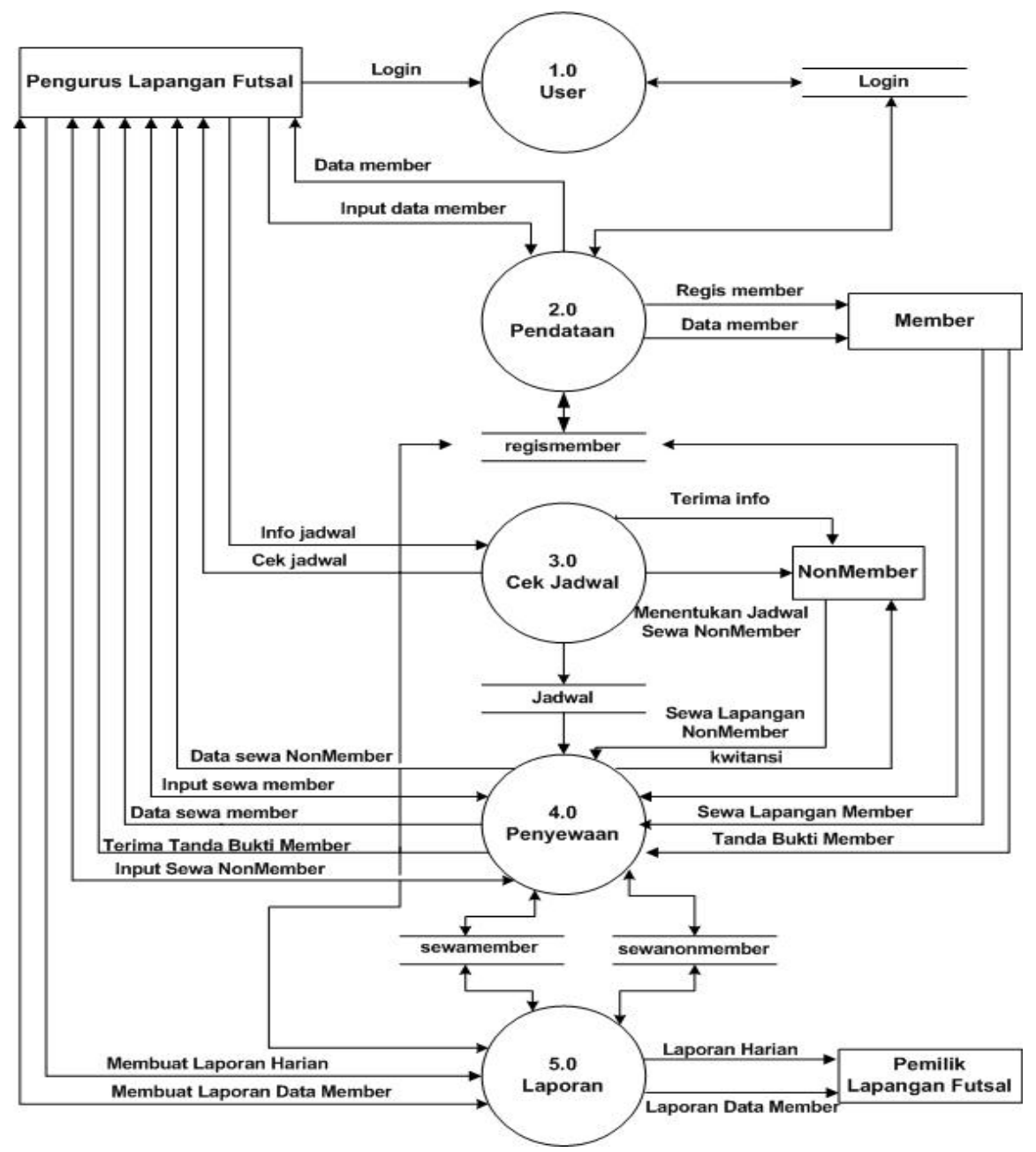

Gambar.2 Diagram Nol yang Diusulkan

\section{Normalisasi}

Normalisasi adalah teknik dengan melakukan

$\begin{array}{lrr}\text { sebuah pendekatan } & \text { bottom-up yang } \\ \text { digunakan } & \text { dalam } & \text { membantu }\end{array}$ digunakan

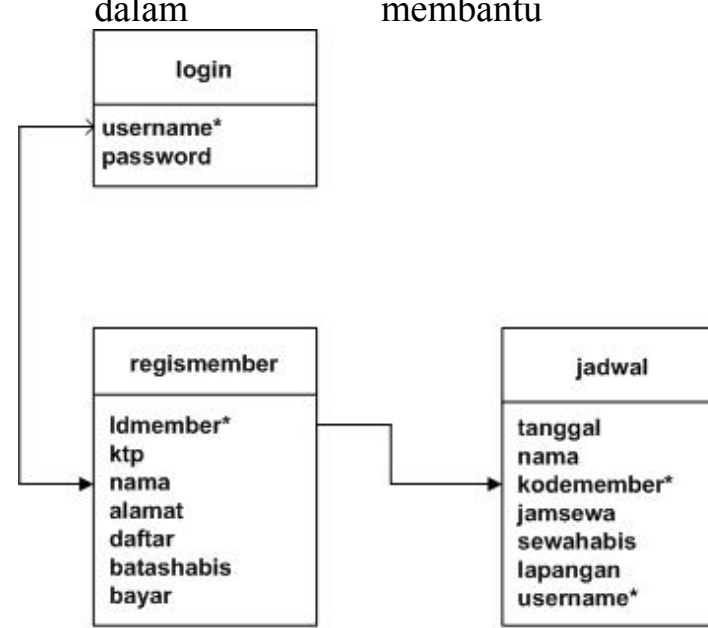
peneliti buat :

mengidentifikasi hubungan. Indrajani 


\section{Entity Relationship Diagram (ERD)}

Entity Relationship (ER) Data model didasarkan pada persepsi terhadap dunia nyata dan tersusun atas kumpulan objekobjek dasar yang disebut entitas dan hubungan antara objek. Entitas adalah suatu atau objek dalam dunia nyata yang dapat dibedakan dari objek lain. Sebagai contoh, masing-masing mahasiswa dan mata kuliah dapat dianggap sebagai entitas.

Entitas digambarkan dalambasis data dengan kumpulan atribut. Misalnya NIM, nama, dan alamat bisa menggambarkan data mahasiswa itu sendiri.

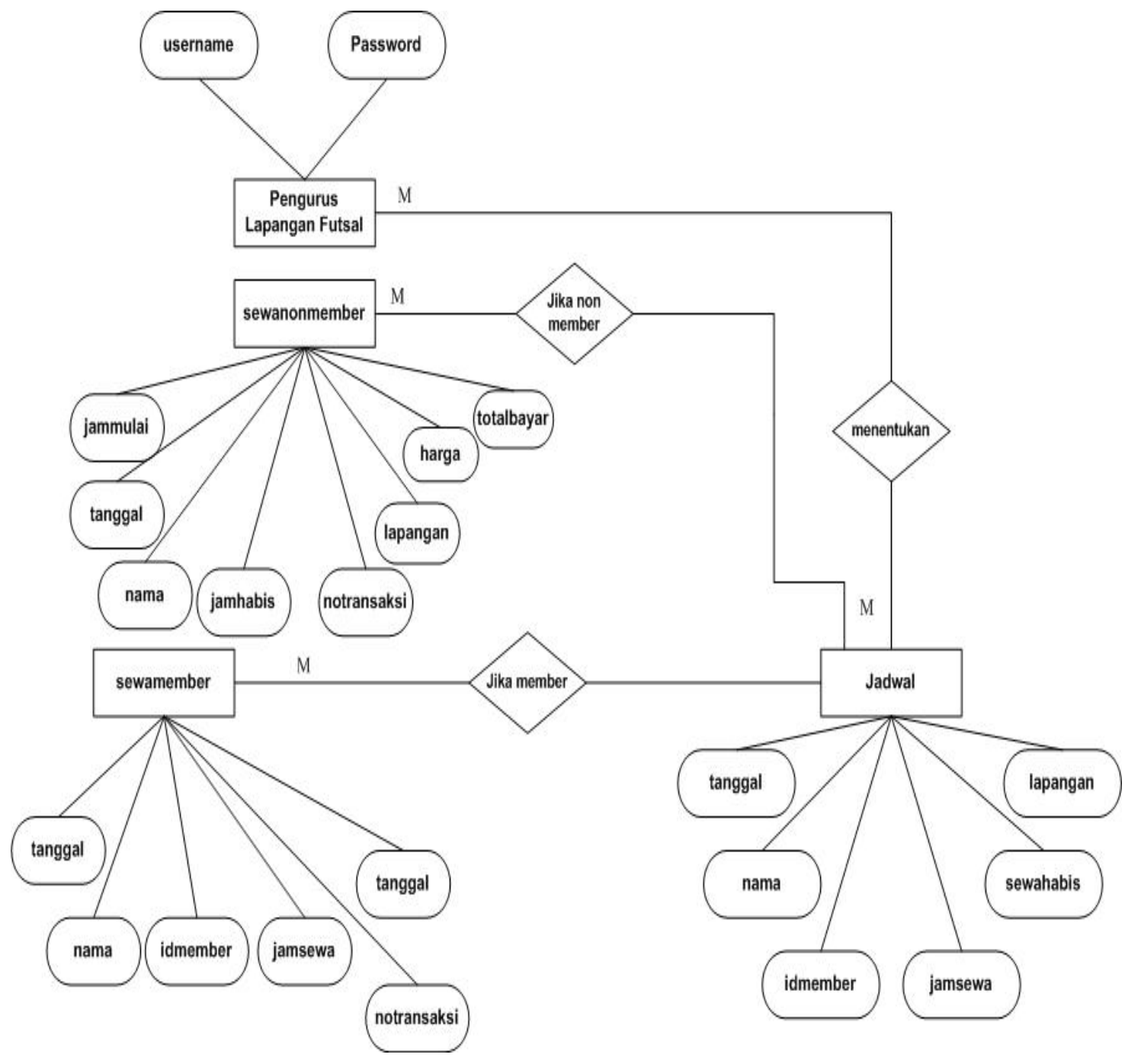

Gambar.2 ERD yang diusulkan

Selanjutnya penulis membuat aplikasi menggunakan java dan database mysql. Berikut ini adalah tampilan dari Perancangan Aplikasi Penyewaan Lapangan Futsal Menggunakan Java Netbeans :

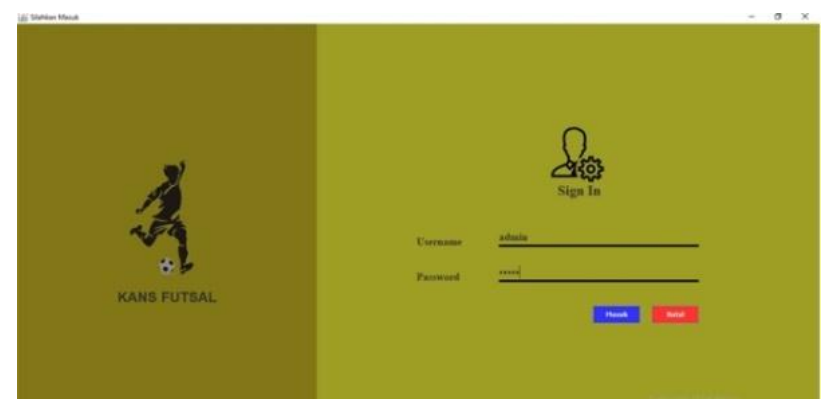

Gambar 3. Login 
Tampilan form login ini muncul di awal saat pengoprasian program sistem sistem administrasi rawat jalan pasien.untuk diisi oleh admin sebagai user. Masukkan username dan password yang sesuai dengan hak akses supaya bisa mengoprasikan sistem administrasi rawat jalan pasien. Jika username dan password sesuai, maka akan masuk kepada tampilan Menu Utama.

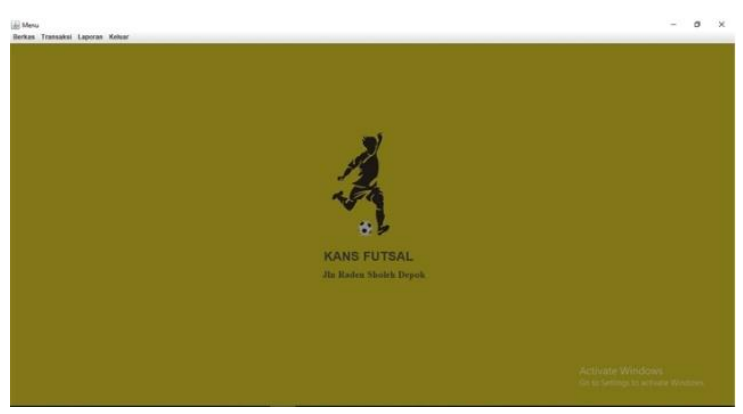

Gambar 5. Menu Utama

Tampilan Menu pada Perancangan Sistem Aplikasi Penyewaan Lapangan Futsal di Kans Futsal. form menu terdiri dari 4 menu : Berkas, Transaksi, Laporan, dan Keluar.

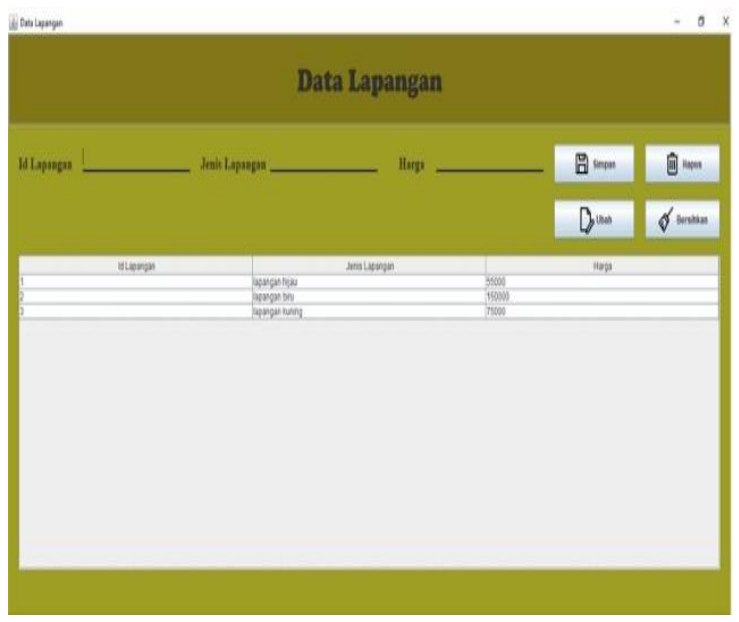

Gambar 6. Tampilan Menu Data Lapangan

Tampilan Form Data Lapangan untuk menginput data lapangan yg ingin dipakai dan jenis lapangan. Lakukan pengisian apabila akan dilakukan penambahan data dan tekan tombol (simpan) untuk menyimpan data, untuk memperbarui data tombol (ubah), untuk menghapus data klik tombol (hapus), untuk membersihkan semua data klik tombol (bersihkan).

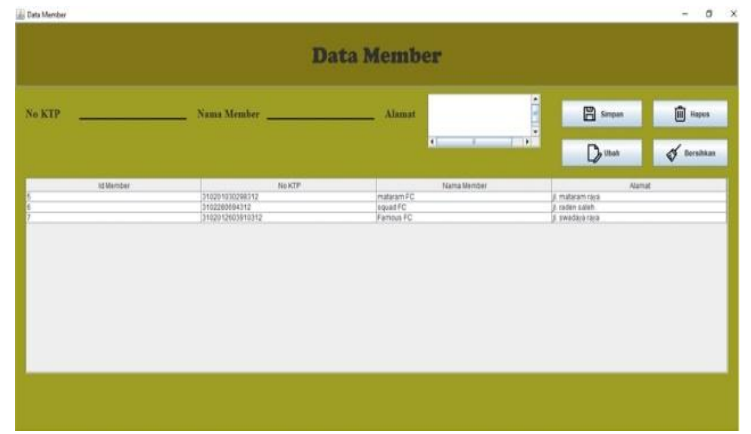

Gambar 7. Tampilan Menu Data Member

Tampilan Form Data Member. Lakukan pengisian apabila akan dilakukan penambahan data dan tekan tombol (simpan) untuk menyimpan data, untuk memperbarui data tombol (ubah), untuk menghapus data klik tombol (hapus), dan pilih tombol (bersihkan) apabila ingin menghapus member yang sudah tidak aktif.

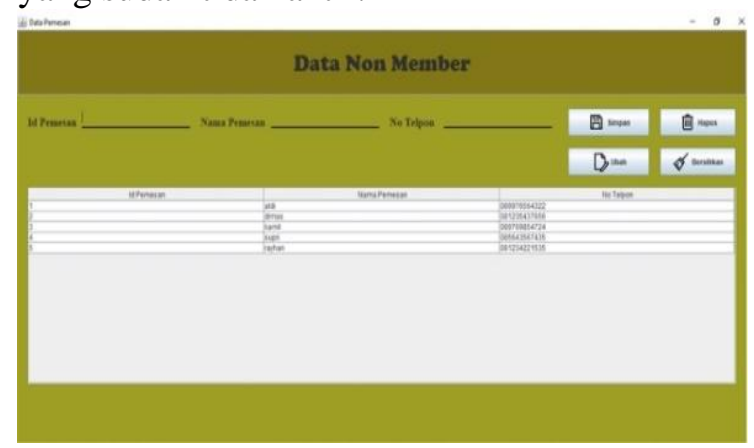

Gambar 8. Tampilan Data Non Member

Tampilan Form Data Non Member. Lakukan pengisian apabila akan dilakukan penambahan data dan tekan tombol (simpan) untuk menyimpan data, untuk memperbarui data tombol (ubah), untuk menghapus data klik tombol (hapus), dan pilih tombol (bersihkan) apabila ingin menghapus data non member.

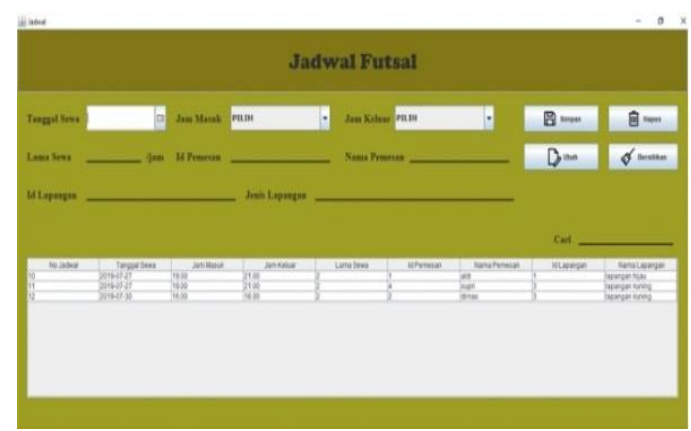


Gambar 9. Tampilan Menu Jadwal Pemesanan

Tampilan Form Jadwal Pemesanan. Lakukan pengisian apabila akan dilakukan penambahan data dan tekan tombol (simpan) untuk menyimpan data, untuk memperbarui data tombol (ubah), untuk menghapus data klik tombol (hapus), dan pilih tombol (bersihkan) apabila ingin menghapus data jadwal futsal.

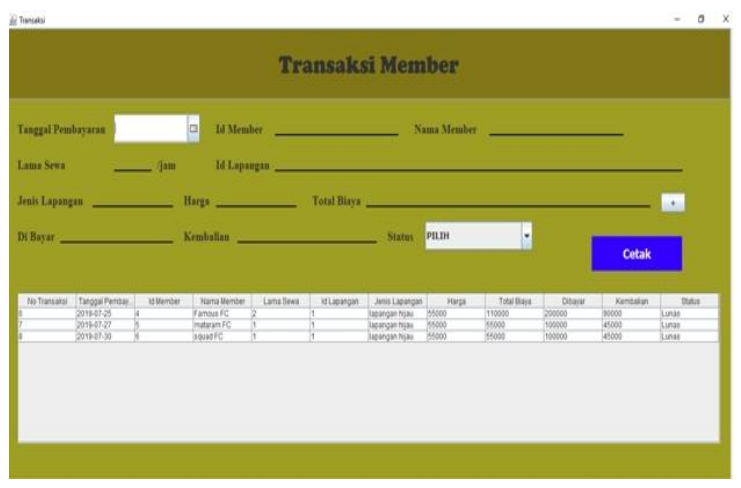

Gambar 10. Tampilan Data Transaksi Member

Tampilan Form Transaksi Member. Pada form transaksi member, dapat mencetak transaksi yang akan dicetak, dapat mengisi kolom-kolom yang telah disediakan, lalu jika ingin mencetak maka dapat langsung menekan button cetak.

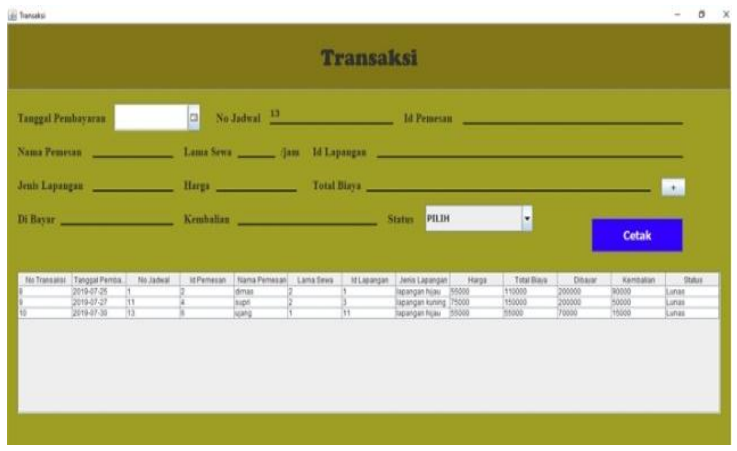

Gambar 11. Tampilan Transaksi Non Member

Tampilan Form Transaksi Non Member. Pada form transaksi non member, user dapat mencetak transaksi yang akan dicetak. User dapat mengisi kolom-kolom yang telah disediakan, lalu jika ingin mencetak maka dapat langsung menekan button cetak.

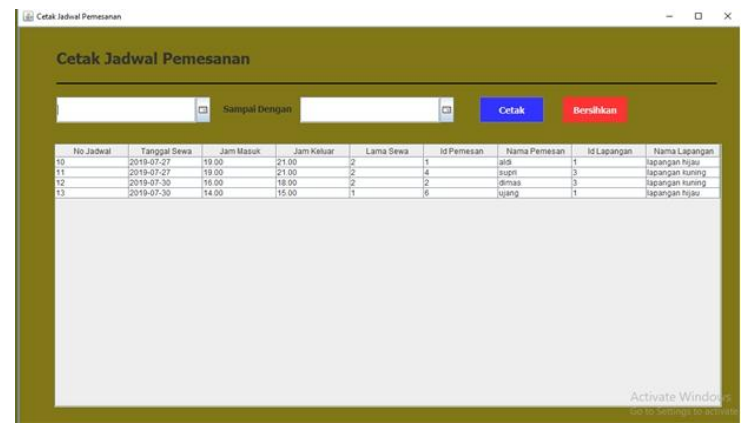

Gambar 12. Tampilan Laporan Jadwal Pemesanan

Tampilan laporan jadwal pemesanan, dapat melakukan perubahan, dan pembersihan jadwal yang sebelumnya sudah masuk ke dalam tabel jadwal pemesanan. Jika ingin mencetak laporan jadwal pemesaan maka dapat langsung menekan button cetak, dan jika ingin membersihkan laporan jadwal pemesanan klik button bersihkan.

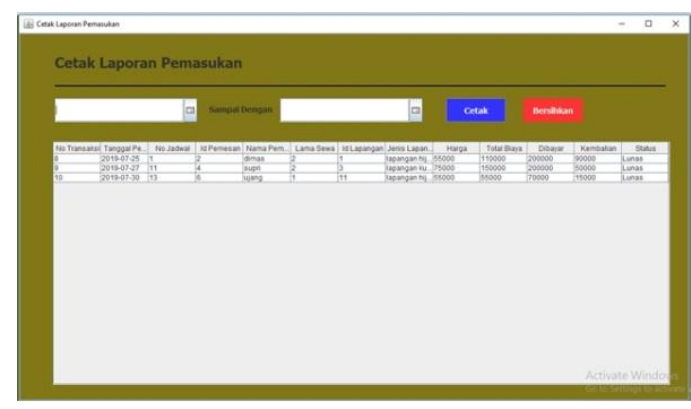

Gambar 13. Tampilan Laporan Pemasukkan

Tampilan Laporan Pemasukkan ini berisikan seluruh data pemasukkan dari member maupun non member. Setelah data sewa member dan non member sudah dimasukkan maupun dirubah maka data sewa member dan non member akan langsung masuk ke dalam form laporan pemasukan. Data yang sudah masuk pun dapat langsung dicetak.

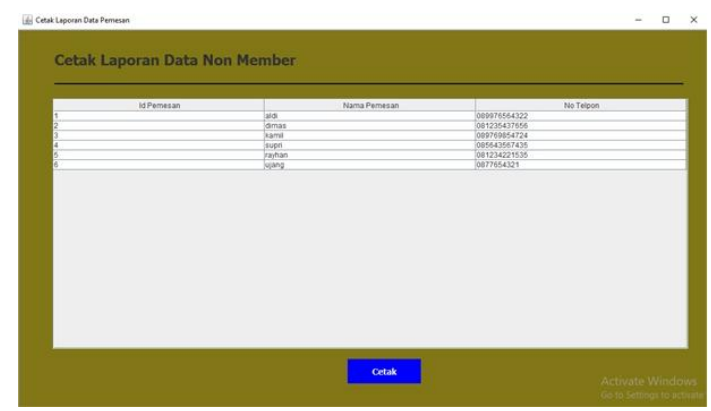

Gambar 14. Tampilan Laporan Data Non Member 
Tampilan Laporan Data Non Member ini berisikan seluruh data dari non member. Setelah data sewa non member sudah dimasukkan maupun dirubah maka data sewa non member akan langsung masuk ke dalam form laporan data sewa non member. Data yang sudah masuk pun dapat langsung dicetak.

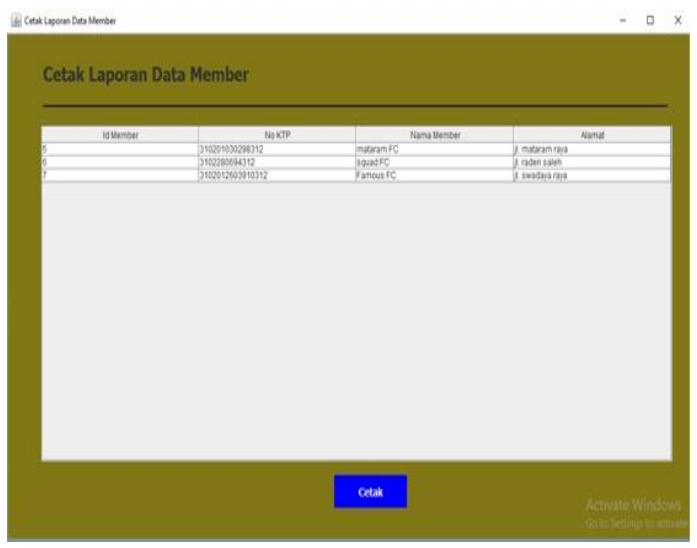

Gambar 15. Tampilan Laporan Data Member

Tampilan Laporan Data Member ini berisikan seluruh data dari member. Setelah data sewa member sudah dimasukkan maupun dirubah maka data sewa member akan langsung masuk ke dalam form laporan data sewa member. Data yang sudah masuk pun dapat langsung dicetak.

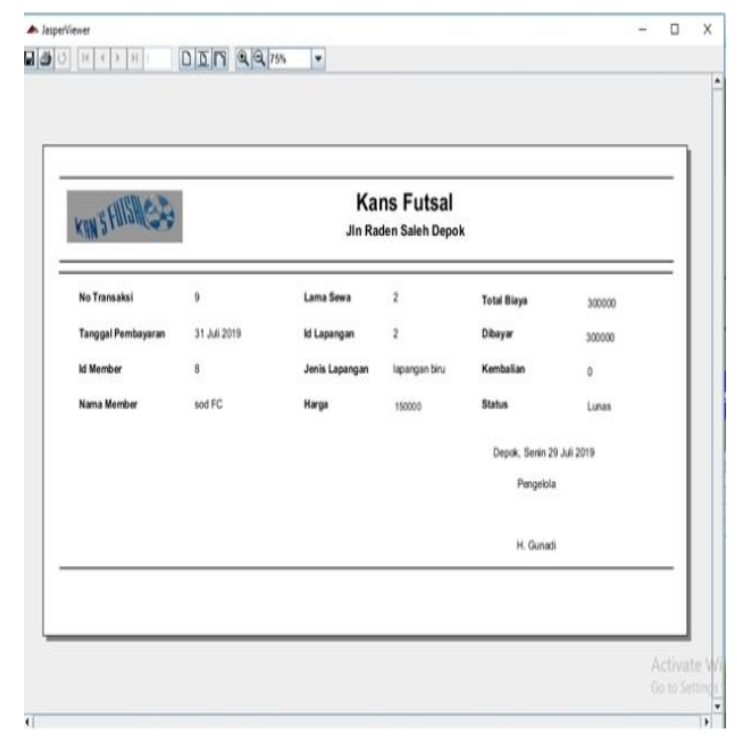

Gambar 16. Tampilan Laporan Transaksi Member

Tampilan Laporan Transaksi Member ini berisikan data dari transaksi member.
Tampilan ini adalah transaksi yang telah dicetak.

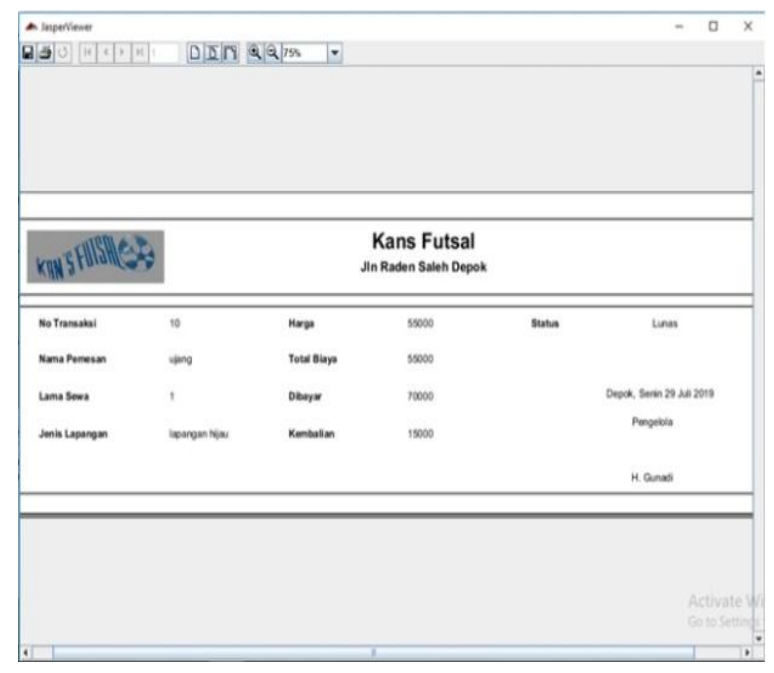

Gambar 17. Tampilan Laporan Transaksi Non Member

Tampilan Laporan Transaksi Non Member ini berisikan data dari transaksi non member. Tampilan ini adalah transaksi yang telah dicetak.

\section{Kesimpulan}

1. Dari pembahasan bab-bab sebelumnya, peneliti dapat menarik kesimpulan bahwa dengan dibuatnya perancangan aplikasi penyewaan lapangan futsal di Kans Futsal yang telah terkomputerisasi sistem pengelolaan data menjadi lebih efektif dan efesien.

2. Dengan adanya aplikasi ini, pengurus lapangan dimudahkan dalam membuat kartu member bagi setiap ada anggota baru yang mendaftar

3. Pengurus lapangan sudah dapat melakukan penginputan jadwal bermain bagi para penyewa yang ingin bermain di Kans futsal tanpa terjadi kekeliruan dalam penjadwalan

4. Pengurus lapangan kans futsal sudah dapat menyimpan data member dan data sewa lapangan yang terkomputerisasi ke dalam aplikasi yang telah dibuat

\section{Daftar Pustaka}

Darmadi, H. (2013). Metode Penelitian Pendidikan dan Sosial. Alfabeta.

Habil, I. M., \& Bunyamin. (2015). 
Pengembangan Sistem Informasi Penyewaan Lapang di Dudirman Futsal. Jurnal Algoritma Sekolah Tinggi Teknologi Garut, 12(1), 1-10. sttgarut.ac.id/jurnal/index.php/algoritma /article/download/225/204

Indrajani. (2011). Database Design (Case Study All In One). PT. Elex Media Komputindo.

Kristanto, A. (2011). Perancangan Sistem Informasi dan Aplikasinya. Gava Media.

Maimunah; Hariyansyah; Jihadi, G. (2017). Rancang Bangun Sistem Aplikasi Penyewaan Lapangan Futsal Berbasis Web. Seminar Nasional Teknologi Informasi Dan Multimedia 2017 STMIK AMIKOM Yogyakarta, 4 Februari 2017 ISSN 2302-3805, 7-12.

Simarmata, Janner. Prayudi, I. (2010). Basis Data. Andi Offset, CV.

Sutabri, T. (2012). Analisis Sistem Informasi. In Analisa Sistem Informasi. 